\title{
Otogenic pneumocephalus secondary to recurrent cholesteatoma and associated temporal bone cerebrospinal fluid leak
}

\author{
Johannes Christiaan Oosthuizen, Fintan Wallis, John Fenton
}

\section{CASE REPORT}

A 79-year-old diabetic male was presented to the emergency department with a one day history of a mild frontal headache and watery discharge from his right ear. His past medical history included previous mastoid surgery, performed more than 50 years ago. The procedure was complicated by postoperative intracranial abscess formation which required neurosurgical intervention and unfortunately resulted in loss of right sided visual acuity. Regrettably, the patient did not attend for continued follow-up and the last contact with the Otolaryngology service had been more than 25 years ago. Examination revealed clear pulsatile otorrhea from the right ear and a sample sent for Beta 2 transferrin testing confirmed the presence of a cerebrospinal fluid (CSF) leak. Microscopic examination of the external auditory canal demonstrated an inflamed external auditory canal with a significant amount of keratin debris, consistent with likely recurrent cholesteatoma, visible beyond a narrow isthmus. A contrast computed tomography (CT) scan was requested emergently and demonstrated a

Johannes Christiaan Oosthuizen ${ }^{1}$, Fintan Wallis ${ }^{2}$, John Fenton ${ }^{3}$

Affiliations: ${ }^{1} \mathrm{MBChB}, \mathrm{MRCSI}$, DOHNS, Department of Otorhinolaryngology, Head and Neck Surgery, Limerick University Hospital, Dooradoyle, Limerick, Co. Limerick, Republic of Ireland; ${ }^{2} \mathrm{MB}$ BCh, FRCR, Department of Radiology, Limerick University Hospital, Dooradoyle, Limerick, Co. Limerick, Republic of Ireland; ${ }^{3}$ Department of Otorhinolaryngology, Head and Neck Surgery, Limerick University Hospital, Dooradoyle, Limerick, Co. Limerick, Republic of Ireland.

Corresponding Author: Mr. Johannes Christiaan Oosthuizen, MBChB, MRCSI, DOHNS, Department of Otorhinolaryngology, Head and Neck Surgery, Limerick University Hospital, Dooradoyle, Limerick, Co. Limerick, Republic of Ireland; Tel: +353 (061) 301111; Fax: +353 (061) 301165; Email: C.oosth@gmail.com

Received: 11 April 2013

Accepted: 28 May 2013

Published: 01 October 2013 significant amount of intra-ventricular free air (Figure 1) as well as the previous posterior craniotomy defect (arrow). High resolution images of the temporal bone confirmed extensive soft tissue opacification of the middle ear cavity and a defect in the tegmen tympani.

Magnetic resonance imaging (MRI) scan was performed which on the coronal images (Figure 2) demonstrated extension of the lateral ventricle to the temporal bone and localized ventriculitis and meningeal enhancement. The diagnosis of otogenic pneumocephalus, secondary to recurrent cholesteatoma with associated temporal bone CSF leak was made. Unfortunately, the patient developed fulminant meningitis whilst being prepared for surgery, which resulted in multiorgan failure despite maximal medical care and ultimately proved fatal.

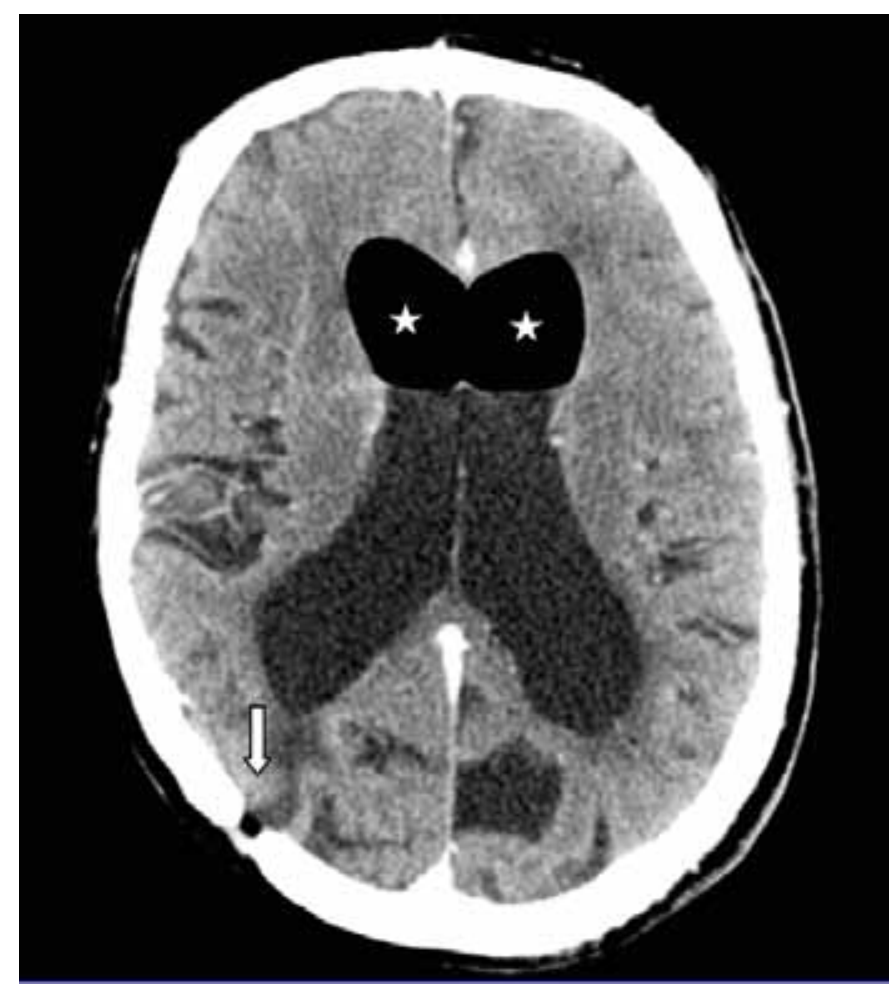

Figure 1: Computed tomography brain, pneumocephalus (Stars), right posterior craniotomy defect (arrow). 


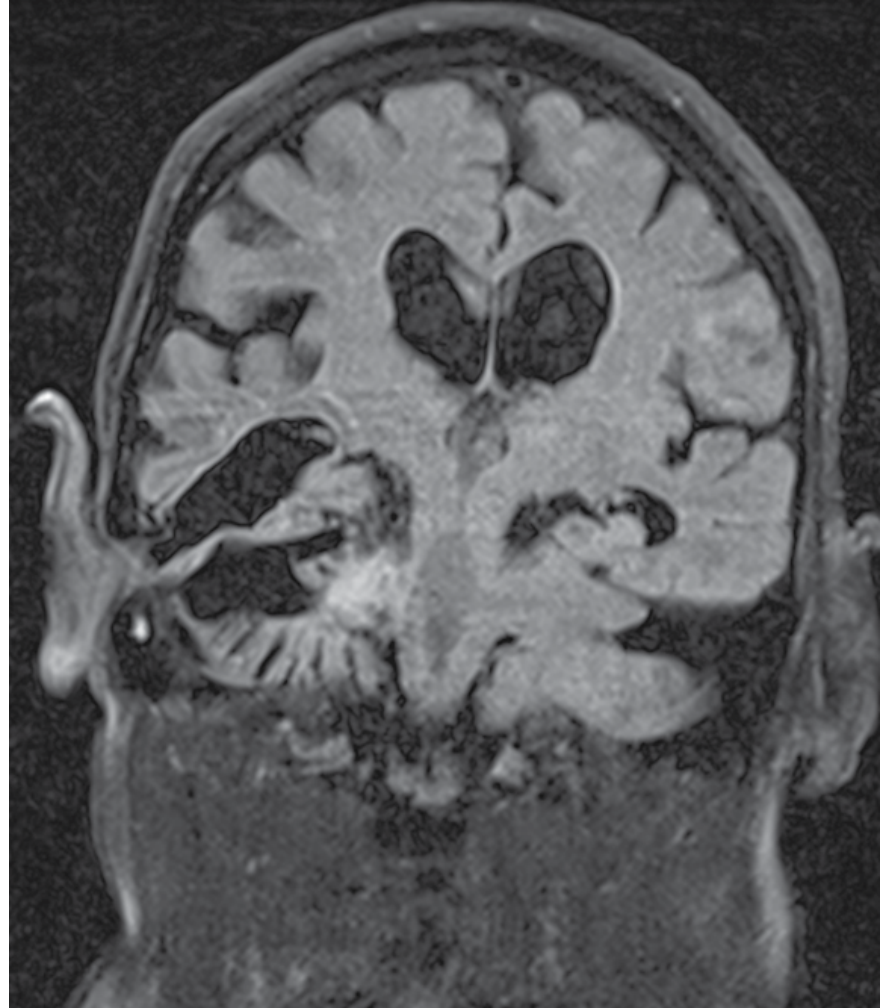

Figure 2: Magnetic resonance imaging, T2-weighted fluid attenuated inversion recovery sequence.

\section{DISCUSSION}

Pneumocephalus, also referred to as aerocoele is defined as the present of air within the cranial cavity. It was first described by Chiari in 1884 during a postmortem of a patient with ethmoiditis [1]. It was not, however, until 1926 that the first case of otogenic pneumocephalus was described [2]. The development of pneumocephalus is reliant upon a defect in the cranial cavity which allows air to enter and typically occurs between the temporal bone and the middle or posterior cranial fossa [3]. Etiological factors associated with the development of otogenic pneumocephalus include trauma, otitis media, surgical intervention, congenital defects and either benign or malignant neoplastic processes $[1,3]$. The presenting features of these patients can often be vague and include headache, lethargy, disorientation and meningism [4]. In the presence of raised intracranial pressure secondary to pneumocephalus; nausea, vomiting and papilledema are commonly encountered and surgical decompression is required as a matter of urgency in the instance of a tension pneumocephalus $[1,5]$. Entry of air into the cranial cavity occurs through one of two mechanisms $[3,6]$. The first is secondary to a ball valve effect where raised nasopharyngeal pressure, secondary to straining or nose blowing, forces air through the defect where after the subsequent increase in intracranial pressure results in trapping of the air within the intracranial space [3]. The second mechanism is due to a significant and continuous
CSF leak which results in a relatively negative intracranial pressure which allows the lost CSF to be replaced by air and is also referred to as the 'inverted bottle' effect [2-4, $6]$.

A history of mastoid surgery, trauma or clinical findings suggestive of CSF otorrhea (which should be confirmed with a Beta 2 transferrin assay) should raise the suspicion of pneumocephalus [1]. Computed tomography scan is the first line investigation of choice and is capable of identifying as little as $0.5 \mathrm{~mL}$ of air within the cranial cavity $[1,4]$. The use of MRI scan serves as a useful adjunct in the investigation as demonstrated by the case in question and is particularly helpful in the localization of the defect [2].

The management of pneumocephalus is dependent upon the etiology. However, surgical intervention is indicated in patients that fail conservative management with persistent CSF leak, progression of the intracranial collection or a tension pneumocephalus [3]. Conservative measures include bed rest, elevation of the patients head by 20-30 degrees and intravenous antibiotics [1]. Various surgical techniques have been described in the management of these cases and include either an extra or intracranial approach [4]. Where feasible these defects should preferentially be approached via the extracranial route as this technique is associated with lower morbidity and mortality rates.

\section{CONCLUSION}

Otogenic pneumocephalus is an infrequently encountered clinical entity that can have vague presenting symptoms and a high index of clinical suspicion is necessary to diagnose this condition.

$* * * * * * * * *$

Oosthuizen JC, Wallis F, Fenton J. Otogenic pneumocephalus secondary to recurrent cholesteatoma and associated temporal bone cerebrospinal fluid leak. International Journal of Case Reports and Images 2013;4(10):586-588.

$* * * * * * * * *$

doi:10.5348/ijcri-2013-10-386-CI-15

$* * * * * * * * *$

\section{Author Contributions}

Johannes Christiaan Oosthuizen - Substantial contributions to conception and design, Acquisition of data, Analysis and interpretation of data, Drafting the article, Revising it critically for important intellectual content, Final approval of the version to be published Fintan Wallis - Substantial contributions to conception and design, Drafting the article, Revising it critically 
for important intellectual content, Final approval of the version to be published

John Fenton - Substantial contributions to conception and design, Drafting the article, Revising it critically for important intellectual content, Final approval of the version to be published

\section{Guarantor}

The corresponding author is the guarantor of submission.

\section{Conflict of Interest}

Authors declare no conflict of interest.

\section{Copyright}

(C) Johannes Christiaan Oosthuizen et al. 2013; This article is distributed under the terms of Creative Commons attribution 3.0 License which permits unrestricted use, distribution and reproduction in any means provided the original authors and original publisher are properly credited. (Please see www.ijcasereportsandimages.com/ copyright-policy.php for more information.)

\section{REFERENCES}

1. Lee DH, Cho HH, Cho YB. Pneumocephalus secondary to mastoid surgery: a case report. Auris Nasus Larynx 2007;34(1):91-3.

2. Chee NW, Niparko JK. Imaging quiz case 1. Otogenic pneumocephalus with temporal bone cerebrospinal fluid (CSF) leak. Arch Otolaryngol Head Neck Surg 2000;126(12):1499,503.

3. Lefantzis D, Triantos S, Vontetsianos H, Dokianakis G. An unusual case of otogenic pneumocephalus. J Laryngol Otol 1998;112(12):1179-80.

4. Ciorba A, Berto A, Borgonzoni M, Grasso DL, Martini A. Pneumocephalus and meningitis as a complication of acute otitis media: case report. Acta Otorhinolaryngol Ital 2007;27(2):87-9.

5. Dubey SP, Jacob O, Gandhi M. Postmastoidectomy pneumocephalus: case report. Skull Base 2002;12(3):167-3.

6. Villa RA, Capdevila A. Images in clinical medicine. Spontaneous otogenic pneumocephalus. N Engl J Med 2008;358(12):e13.
Access full text article on other devices

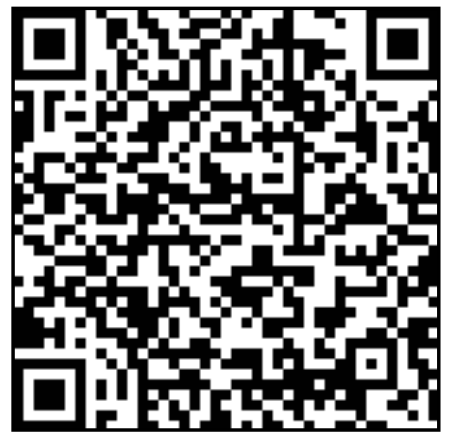

Access PDF of article on other devices

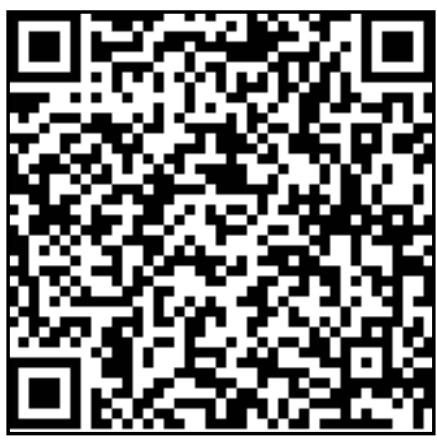

